\title{
Pricing credit derivatives
}

\author{
Tamal Banerjee, Mrinal K. Ghosh* and Srikanth K. Iyer
}

Department of Mathematics, Indian Institute of Science, Bangalore 560 012, India

\begin{abstract}
The financial crisis set off by the default of Lehman Brothers in 2008 leading to disastrous consequences for the global economy has focused attention on regulation and pricing issues related to credit derivatives. Credit risk refers to the potential losses that can arise due to the changes in the credit quality of financial instruments. These changes could be due to changes in the ratings, market price (spread) or default on contractual obligations. Credit derivatives are financial instruments designed to mitigate the adverse impact that may arise due to credit risks. However, they also allow the investors to take up purely speculative positions. In this article we provide a succinct introduction to the notions of credit risk, the credit derivatives market and describe some of the important credit derivative products. There are two approaches to pricing credit derivatives, namely the structural and the reduced form or intensity-based models. A crucial aspect of the modelling that we touch upon briefly in this article is the problem of calibration of these models. We hope to convey through this article the challenges that are inherent in credit risk modelling, the elegant mathematics and concepts that underlie some of the models and the importance of understanding the limitations of the models.
\end{abstract}

Keywords: Credit risk, default probability, structural approach, reduced form approach, incomplete information.

\section{Introduction}

ON 15 September 2008, Lehman Brothers, a large investment bank in Wall Street, New York, USA, filed for bankruptcy protection. The events leading up to this default event set off a tsunami that submerged global financial markets. Stock markets across the world crashed. A severe recession across much of the developed world followed, impacting economies of developing countries that depended heavily on exports to the developed countries. A sovereign debt crisis across many of the countries of the Euro zone threatened to unravel the Euro. The world economy is still struggling to recover from the impact of the crisis.

We first give a brief account of two credit derivatives, the motivations and challenges in pricing these instru-

*For correspondence. (e-mail: mkg@math.iisc.ernet.in) ments. Later we provide a more precise mathematical description and discuss some of the pricing models.

At the heart of the financial crisis were financial instruments called mortgage-backed collateralized debt obligations (CDOs). Banks making home loans across the United States sold these loans to large investment banks such as the Lehman Brothers. This enabled the banks to free up regulatory capital which otherwise they would have had to set aside to cover for the losses arising from defaults on the home loans. The investment bank then pooled these loans and sold them to investors ranging from pension funds to school boards. The entire receivables (notional) of the pool was divided into tranches such as the equity, mezzanine and the senior tranches. As borrowers from the pool made their monthly payments, these would be first distributed among investors starting from the senior tranche. Suppose the total notional of the pool was 1, and say the equity, mezzanine and senior tranches respectively, had lower and upper cut-off points $\left[0, d_{1}\right),\left[d_{1}, d_{2}\right)$ and $\left[d_{2}, 1\right]$. The first losses are borne by the investors of the equity tranche and hence these tranches received high returns. As long as the total losses in the pool did not exceed $d_{1}$, investors in the mezzanine tranche would receive the full payment due to them. Once losses exceed $d_{1}$ investors in the equity tranche would receive nothing. When losses exceed $d_{1}$ but are lower than $d_{2}$, investors in the mezzanine tranches would receive part payments depending on the extent of the losses. The senior tranche investors would still be protected. The idea was that though the chance of individual loans defaulting is high, the chance that the total losses exceed $d_{2}$ would be low. This was sought to be justified due to the geographical diversity of the loan portfolio. The pricing of the different tranches was determined by the rating agencies. It is clear that the above instrument has obvious economic advantages in that it increases the liquidity of otherwise illiquid assets such as home loans, thus freeing up capital. The senior tranches were often given the highest rating but gave higher returns than other similarly rated bonds, thus opening up a huge investment avenue for institutions such as pension funds, local governments, etc. that were mandated only to invest in highly rated securities.

The incentive structure, however, had no checks and balances as this market was largely unregulated unlike the normal operations of banks and insurance firms. The rating agencies were paid to rate and so had an incentive to provide higher ratings. Investment bankers and traders 
were given huge bonuses to take heavy short-term risks. More loans meant more money with few risks for banks and so there was incentive to relax eligibility conditions for loans. Everything was fine as long as the interest rates were low and money was easily available and housing prices kept moving up. Once the interest rates started going up and the economic growth slowed down, the bubble burst. When the housing bubble burst, there were huge losses as home owners who found the value of their homes less than the mortgage payments started defaulting in large numbers. Investors in the senior tranches realized that the value of their supposedly highly rated securities was no better than junk bonds. Investors of these bonds had bought insurance to cover for potential losses. However, since this part of the insurance industry was unregulated, the investors found that the insurance companies had not set aside enough capital to cover for potential losses. The insurers were unprepared as these securities were supposed to have the highest ratings. Another significant factor contributing to the meltdown was that banks were highly leveraged, that is, had high debt to equity ratio. Prior to the crisis, Lehman Brothers was leveraged $31: 1$. This meant that when asset prices rise, the bank makes huge profits. But a few percentage fall in the prices can wipe out the entire capital of the bank. Earlier to the collapse of Lehman Brothers, Bear Sterns, another investment bank was bailed out by the Federal reserve on 14 March 2008. Investment banks took huge risks in the hope that they too would be bailed out since they are too big to fail. However, collapse of a large bank such as Lehman Brothers froze the financial system. Banks were unwilling to lend to each other since no one was sure how much of the toxic assets others held. Most of these complex derivative products were off-balance sheet transactions. The Federal Government and other reserve banks had to eventually step in with a huge tax-payer-funded bailout, leading to strong protests against the privitization of profits and the socialization of the losses.

This has bought to sharp focus the methods and models used by the rating agencies and the pricing procedures at trading desks. We now focus on some of these issues. The idea that the loans across geographies would behave somewhat independently was obviously a blatantly incorrect assumption given that home prices are highly correlated with the interest rate and the performance of the economy. Where correlations were indeed sought to be modelled, many models such as the popularly used copulabased models ${ }^{1}$ were known to be insufficient to capture large correlated movements in the defaults. A copula is a parametrized multivariate distribution that seeks to incorporate dependencies between variables with given marginal (individual) distributions. The most popular copula model used were the Gaussian copulas, known so due to the use of the multivariate Gaussian distribution to induce correlations among random variables associated with individual entities in a portfolio. These were easy to use and were popular among traders, but were static and had weak theoretical justification. Further for large portfolios, these copulas were cumbersome requiring large simulations, thus exacerbating model risks. Most likely, the quantitative analysts knew of the limitations of the Gaussian copulas. In fact the Wall Street Journal carried a full-length article deriding the Gaussian copulas. Unfortunately the analysts reported to the traders and not to the management, and thus clearly their opinion was not welcome or ignored. In other models, such as the KMV model described later in this article, a certain logic was used to develop the model up to a point. Then since the model did not fit the data well enough, it was tweaked by introducing arbitrary parameters. Such arbitrary changes meant that the effect of the parameter on the price and also the ability of the model to react to changes in the market would be difficult to understand and quantify.

Another problem is that some of the models such as the structural models based on Merton's framework, require estimation of the parameters governing the evolution of the asset price of a firm. Since asset price of a firm is not known, it has to be inferred from the traded equity price. This leads to many mathematical difficulties. Further, there could be fundamental assumptions in the model such as that the assets of a firm are traded, which obviously does not hold true. The impact of such approximations is hard to quantify.

A third and crucial problem is one of calibration of the models. The basic premise of the classical parameter estimation problem, where the past behaviour is supposed to continue into the future does not quite hold in financial markets. The prices obtained by most models where parameters are estimated from past data turn out to be considerably lower than market prices even after adjusting for factors such as transaction costs, etc. that are not included in the model. A problem with this approach is that the model would not predict a crisis such as the one that stuck in 2008, unless the past data contained such an occurrence. Since defaults prior to September 2008 were rare, it would have been hard to find models that would have predicted such a severe clustered occurrence of defaults. Thus the question arises whether rating agencies would have been able to justify higher prices using mathematical models. Another problem in this approach is due to the so-called incompleteness of the market, where the mathematical model throws up many prices, all of which are free of what is known as arbitrage. The question then is which of the several prices should one pick?

An alternate approach which is extensively used and one that circumvents the above problem and is quite peculiar to the area of finance is to calibrate (or estimate the parameters of the model) based on the current prices of liquidly traded securities rather than the past data. The argument is that these prices represent the market view of future risks. Models calibrated thus will closely match the 
current market prices used to calibrate them. These models are then used to price more complex over-the-counter securities which are the main source of profits. Such models may suffer from non-robust parameter estimation due to irrational exuberance and over-reactions of the market and may lead to self-fulfilling prophecies.

While credit derivatives are designed to mitigate the adverse impact of credit-related events, they also allow investors to take up purely speculative positions as we illustrate next. One of the simplest yet important credit derivative product is a credit default swap (CDS). It is a contract that provides insurance against the risk of default by a particular firm. These constitute a large part of the credit derivatives market. A bank holding a large quantity of bonds issued by a firm A, may wish to cover for losses that may arise if the firm defaults. It enters into a twoyear CDS for say US\$ 10 million at price of 80 bps (basis points) annually. Suppose that the premium payments are to be made on a quarterly basis. Then the bank pays to the seller of the CDS US\$20,000 each quarter until default or the end of the contract, whichever is earlier. If the firm does not default, the bank would have made a total payment of US\$160,000 over the two-year period, at the end of which the contract expires. On the other hand, suppose that the firm defaults in the middle of the third quarter since the contract came into force. Then the bank receives US\$ 10 million from the seller of the CDS and it would have paid US\$40,000 plus a fraction of the amount due for the third quarter. The fundamental question again is the computation of the premium. Alternatively, the bank could sell a CDS of a firm $B$ whose default it feels is uncorrelated with that of firm $A$. This way it can reduce the net amount it will have to pay for the protection it bought on firm $A$. Since banks are issuing CDS contracts to each other, there is also the factor of counterparty risk. The bank selling the CDS may not be in a position to honour the contract in case of the default event. This risk is most often ignored in mathematical models and must be accounted for separately. An investor who feels that the credit quality of a firm is likely to deteriorate could take up a speculative position by buying a CDS on that firm. If the rating of the firm indeed deteriorates, then the CDS premium of the firm will go up and the investor can then make a profit by selling the CDS. For an excellent introduction to some of the above ideas, see ref. 2.

There are primarily two quantitative approaches ${ }^{3,4}$ to credit risk modelling, namely the structural and the reduced form approach. In the structural approach (some examples include refs 5-8) also known as the firm value approach, explicit assumptions are made about the dynamics of a firm's assets, its capital structure, its debt and shareholders. A firm defaults when its asset value reaches a certain lower threshold, defined endogenously within the model. The recovery rates in the structural approach are also frequently specified endogenously within the model as some function of the value of the firm. The structural model has a simple capital structure consisting of one debt obligation and one type of equity. The equity process of the company is traded publicly. The market value of the company's debt obligation is the value of the defaultable bond issued by it. The debt is assumed to have a cash profile of a zero coupon bond maturing at a fixed time $T$, and interest adjusted face value $K$. Thus, the firm is obliged to repay the amount $K$ to its bondholders at the maturity $T$. The firm is said to default if it is unable to fulfil its debt obligations. In such a case, the bondholders take over the firm and recover whatever they could from the remaining assets. In this case the equity holders receive nothing in case of default or the firm could be restructured. Some of the important factors in modelling credit risk are the choice of an appropriate model for the rate of interest, the probability of default and the strategy by which one hedges the risk of default.

In the intensity-based approach, frequently referred to as the reduced form approach, the firm's asset values and its capital structure are not modelled at all. Instead the dynamics of default are exogenously given through a default rate or intensity. Thus, this approach is silent about why a firm defaults. However, unlike the structural models, here the default occurs without warning at an exogenous default rate, or intensity. As a result, the term structure for the credit spreads are in general better behaved in the reduced form models than the structural ones. Some of the early works in this area are those of Duffie and Singleton ${ }^{9}$ and Jarrow and Turnbull ${ }^{10}$. In these models the default probabilities and timings are based on the notion of arrival intensity of default. For example, in a simple setting, the default timings may be modelled as the first arrival time $\tau$ of a Poisson process with constant mean arrival rate $\lambda$ (also called intensity). The default arrivals may also be modelled by Cox process compound Cox process, compound Poisson process and general point processes (see chapter 5 in ref. 11). For an excellent discussion on the different methodologies for implementing the intensity models, see chapter 7 in ref. 11 .

The rest of the paper is organized as follows. In the next section we describe some of the classical structural models in the credit risk literature along with their limitations. We demonstarte the pricing of defaultable bonds in a structural set-up. We also briefly indicate some of the criticisms of the structural models and ways in which they may be resolved. Next we describe the intensitybased models. We illustrate the pricing of single-name and multi-name credit derivatives in a reduced form set-up. Finally, we conclude with a few remarks.

\section{The structural approach}

This approach originates from the pioneering work of Merton $^{8}$. In this approach (some of the early work can be found in refs 5-8), also known as the firm value 
approach, explicit assumptions are made about the dynamics of a firm's assets, its capital structure, its debt and shareholders. A firm defaults when its asset value reaches a certain lower threshold. The default barrier and the recovery rates are frequently specified endogenously within the model as some functions of the value of the firm. In this section, we describe some of the earliest structural models studied in the literature. They are the Merton's classical model ${ }^{8}$, the Black and Cox model ${ }^{5}$ and the Longstaff-Schwartz model $^{7}$.

\section{Merton's classical model ${ }^{8}$}

This was one of the earliest models for corporate default. In this option-based model, Merton assumed that default takes place if the asset value of the firm falls below the firm's debt. The asset value of the firm $\left\{A_{t}\right\}$ is assumed to follow a geometric Brownian motion (GBM) given by

$$
\mathrm{d} A_{t}=(\mu-\kappa) A_{t} \mathrm{~d} t+\sigma A_{t} \mathrm{~d} W_{t},
$$

where $\mu \in \mathbb{R}, \kappa \in \mathbb{R}$ and $\sigma>0$ denote the gross mean return on the assets, the proportional cash payout rate of the firm and the volatility respectively. The process $\left\{W_{t}\right\}$ is the standard Brownian motion.

This model has a simple capital structure consisting of one debt obligation and one type of equity. Let $E_{t}$ denote the equity process of the company which is traded publicly. Let us denote the market value of the debt obligation of the company by $D_{t}$. The debt is assumed to have a cash profile of a zero coupon bond maturing at a fixed time $T$, and interest-adjusted face value $K$. Thus, the firm is obliged to repay the amount $K$ to its bondholders at the maturity $T$. In case the firm is unable to fulfil its obligations, the bondholders take over the firm. Therefore, the default time in Merton's model is defined by

$$
\tau= \begin{cases}T & \text { if } A_{T}<K, \\ \infty & \text { Otherwise. }\end{cases}
$$

Figure 1 illustrates the default rules in Merton's model. Using Ito's rule (theorem 4.4.6, ref. 12), we obtain from eq. (1)

$$
A_{t}=A_{0} \exp \left(m t+\sigma W_{t}\right),
$$

where $m=\left(\mu-\kappa-1 / 2 \sigma^{2}\right)$. The conditional default probability for the Merton's model is given by ${ }^{4}$

$$
P\left[A_{T}<K \mid A_{t}\right]=\Phi\left(\frac{\log \left(L_{t}\right)-m(T-t)}{\sigma \sqrt{(T-t)}}\right),
$$

where $L_{t}=K / A_{t}$ is the leverage ratio of the firm and $\Phi($. is the standard normal distribution given by

$$
\Phi(x):=\frac{1}{\sqrt{2 \pi}} \int_{-\infty}^{x} \mathrm{e}^{-u^{2} / 2} \mathrm{~d} u .
$$

The asset value of the firm in Merton's model is not observable. Therefore, one of the popular ways for implementing this model is using the Moody's KMV model. This model introduces the notion of distance to default (DD) using the expression (4). For the special case when $T=1$, the DD is defined by ${ }^{11}$

Distance to default $=\frac{\left(\begin{array}{c}\log (\text { Market value of assets })- \\ \log (\text { Default point })\end{array}\right)}{\text { Asset volatility }}$.

In case of no default, the asset value of the firm at maturity is greater than or equal to the face value of the bond. In this case, the bondholders receive their promised payment $K$ and the shareholders gets the remaining amount of $A_{T}-K$. However, if the asset value $A_{T}$ is less than $K$, the firm defaults. In this case, the bondholders take over the firm and lose the amount $K-A_{T}$. Equity becomes worthless because of limited liability. We summarize the above discussions in Table 1. Therefore, the total payoff to the equity holders at the maturity is given by

$$
E_{T}=\left(A_{T}-K\right)^{+}:=\max \left(A_{T}-K, 0\right),
$$

which is identical to the payoff for a European call option on $\left\{A_{t}\right\}$ with strike price $K$, constant dividend rate $\kappa$, and maturity $T$. Therefore, for $t \in[0, T]$, the equity process is a long European call option $C_{t}^{\kappa}$, from the point of view of the equity holders. The option price is determined from Black-Scholes formula ${ }^{12}$

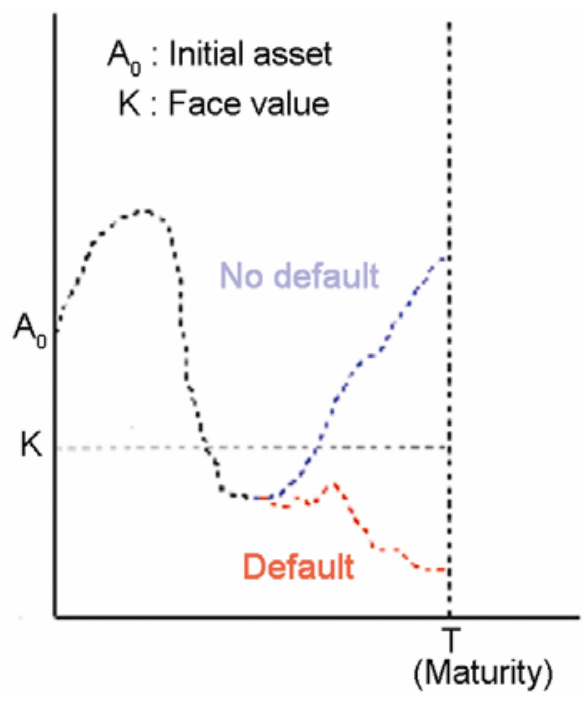

Figure 1. Default behaviour (Merton)

Table 1. Payoff at maturity

\begin{tabular}{lccc}
\hline Case & Assets & Bonds & Equity \\
\hline Default & $A_{T}<K$ & $A_{T}$ & 0 \\
No default & $A_{T} \geq K$ & $K$ & $A_{T}-K$ \\
\hline
\end{tabular}




$$
\begin{aligned}
& E_{t} \equiv C_{t}^{K}=A_{0} \Phi\left(d_{+}\left(A_{t}, T-t\right)\right) \\
&-K \exp (-r(T-t)) \Phi\left(d_{-}\left(A_{t}, T-t\right)\right),
\end{aligned}
$$

where

$$
d_{ \pm}(x, t)=\frac{\left(r-\kappa \pm \frac{1}{2} \sigma^{2}\right) t-\log \left(\frac{K}{x}\right)}{\sigma \sqrt{t}} .
$$

The value of the defaultable bond at the maturity is given by

$$
D_{T}=\min \left(K, A_{T}\right)=K-\max \left(K-A_{T}, 0\right) .
$$

The above payoff is equivalent to that of a portfolio consisting of a default-free loan with face value $K$ maturing at $T$ and a short European put option on $\left\{A_{t}\right\}$ with strike price $K$ and maturity $T$. Therefore, the value of the defaultable bond at time $t$, before maturity is given by

$$
D_{t}=K \exp (-r(T-t))-P_{t}^{\kappa},
$$

where $P_{t}^{\kappa}$ is the price of a put option on the asset $A_{t}$, with constant dividend $\kappa$, strike price $K$ and maturity $T$. The put-call parity for European options gives us

$$
A_{t} \exp (-\kappa(T-t))+P_{t}^{\kappa}=C_{t}^{\kappa}+K \exp (-r(T-t)) .
$$

Using eq. (12), we obtain

$$
D_{t}=A_{t} \exp (-\kappa(T-t))-E_{t},
$$

where $A_{t}$ and $E_{t}$ are obtained from eqs (1) and (8) respectively. Equation (13) gives us the theoretical price of the debt at time $t$. In order to analyse the credit risk of defaultable bonds, one needs to consider their credit spread. Credit spread is the difference between the yield on a defaultable bond and the yield on an otherwise equivalent default-free zero coupon bond. For the Merton's classical model, the spread $S(t, T)$ is given by

$$
S(t, T)=-\frac{1}{T-t} \log \left(\frac{D_{t}}{\exp (-r(T-t))}\right), T>t .
$$

\section{Black and Cox model ${ }^{5}$}

In the Merton's model, default can occur only at the maturity $T$ of the bond. In the Black and Cox model, the default occurs at a random time, when the asset value of the firm falls below a barrier level $J(J<K$, else the bondholders are fully protected). Such models are called first passage models in the literature. In order to define the default event more precisely we introduce the following stopping times

$$
\tau_{1}= \begin{cases}T & \text { if } A_{T}<K, \\ \infty & \text { otherwise. }\end{cases}
$$

Let $\tau_{2}$ be the stopping time given by $\tau_{2}=\inf \{t \in(0, T] \mid$ $\left.A_{t}<J\right\}$ and set $\tau_{2}=\infty$; if the set is empty. Then the default time $\tau$ is given by

$$
\tau=\min \left(\tau_{1}, \tau_{2}\right) .
$$

The default behaviour for this model is illustrated in Figure 2. Therefore, the conditional default probability at time $t$, for this model is given by

$$
\begin{gathered}
1-P\left[\min \left(\tau_{1}, \tau_{2}\right)>T \mid A_{t}\right]=\Phi\left(\frac{\log \left(L_{t}\right)-m(T-t)}{\sigma \sqrt{(T-t)}}\right) \\
+\left(\frac{J}{A_{t}}\right)^{2 m / \sigma^{2}} \Phi\left(\frac{\log \left(J^{2} / K A_{t}\right)+m(T-t)}{\sigma \sqrt{(T-t)}}\right) .
\end{gathered}
$$

The conditional default probability in the Black and Cox model is obviously higher than the Merton's classical model. The default probability for the Merton's model can be calculated as a special case of eq. (17) with $J=0$. The payoff to equity holders in this model is given by

$$
E_{T}=\left(A_{T}-K\right)^{+} I\left\{\hat{M}_{T} \geq J\right\},
$$

where $\hat{M}_{T}=\min _{s \leq t} A_{s}$, and $I\{$.$\} is the indicator function.$ The above payoff corresponds to a European down-and-out call on $A_{t}$ with strike price $K$, barrier $J(<K)$, constant dividend rate $\kappa$ and maturity $T$. Therefore, the value of the equity at an earlier time is given by

$$
\begin{aligned}
E_{t}= & C_{t}^{\kappa}-\exp (-\kappa(T-t)) A_{t}\left(\frac{J}{A_{t}}\right)^{\frac{2(r-\kappa)}{\sigma^{2}}+1} \Phi\left(d_{1}\left(A_{t}, T-t\right)\right) \\
& +K \exp (-r(T-t))\left(\frac{J}{A_{t}}\right)^{\frac{2(r-\kappa)}{\sigma^{2}}-1} \Phi\left(d_{2}\left(A_{t}, T-t\right)\right),
\end{aligned}
$$

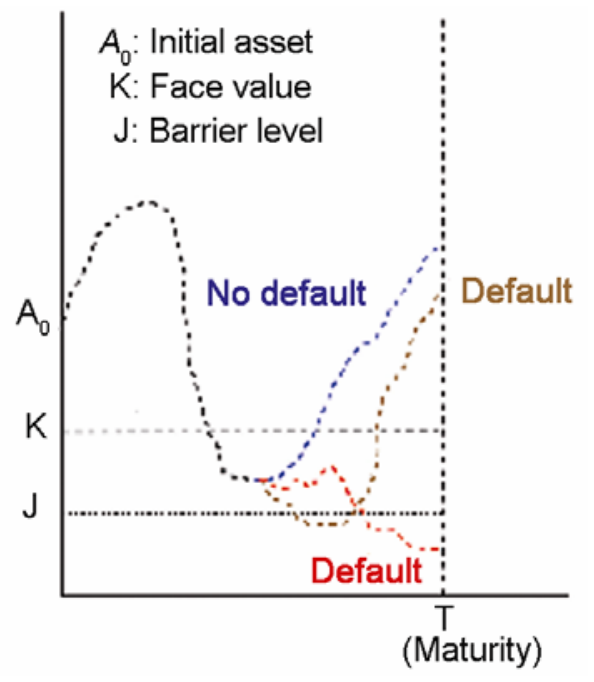

Figure 2. Default behaviour (Black and Cox). 
where

$$
d_{1}(x, t):=\frac{\log \left(\frac{J^{2}}{K x}\right)+\left(r-\kappa+\frac{1}{2} \sigma^{2}\right) t}{\sigma \sqrt{t}},
$$

and

$$
d_{2}(x, t):=\frac{\log \left(\frac{J^{2}}{K x}\right)+\left(r-\kappa-\frac{1}{2} \sigma^{2}\right) t}{\sigma \sqrt{t}},
$$

The value of the defaultable bond at time $T$ is given by

$$
D_{T}=K-\left(K-A_{T}\right)^{+}+\left(A_{T}-K\right)^{+} I\left\{\hat{M}_{T}<J\right\},
$$

which is equivalent to a portfolio consisting of a risk-free loan with face value $K$, a short European put on $A_{t}$ with strike price $K$, constant dividend rate $\kappa$ and maturity $T$, and a long European down-and-in call on $A_{t}$ with strike price $K$, dividend rate $\kappa$, barrier $J$ and maturity $T$. Therefore, the value of the defaultable bond at an earlier time $t$ is given by

$$
\begin{aligned}
D_{t}= & A_{t} \exp (-\kappa(T-t))-C_{t}^{\kappa} \\
& +\exp (-\kappa(T-t)) A_{t}\left(\frac{J}{A_{t}}\right)^{\frac{2(r-\kappa)}{\sigma^{2}}+1} \Phi\left(d_{1}\left(A_{t}, T-t\right)\right) \\
& -K \exp (-r(T-t))\left(\frac{J}{A_{t}}\right)^{\frac{2(r-\kappa)}{\sigma^{2}}-1} \Phi\left(d_{2}\left(A_{t}, T-t\right)\right) .
\end{aligned}
$$

In the previous two models the interest rates were deterministic. There are structural models with stochastic interest rates. For instance, in the Longstaff and Schwartz Model $^{7}$, the interest rate is stochastic and evolves according to the Vasicek model. Bielecki and Rutkowski ${ }^{3}$ discuss various other important structural models in the literature.

The structural models such as the one described above do not produce credit spreads consistent with the empirical findings. This is because the default event in these models does not come as a total surprise. Default events being predictable produce credit spreads much lower than those observed in reality. Furthermore, contrary to the empirical findings, credit spreads in these models are close to zero for bonds with short maturities. The term structure of credit spread for a defaultable bond in the Merton's classical model is shown in Figure $3 a$ and the default probability in the model is illustrated in Figure $3 b$. The model parameters in both cases are set as: $r=0.06, \mu=0.07, \kappa=0.03, \sigma=0.2$ and $L=0.40$.

Several attempts have been made to obtain more realistic credit spreads in the structural models, such as in refs 5-7, which are all extensions of the Merton's model.
Bielecki and Rutkowski ${ }^{3}$, provide an excellent description of the different extensions of Merton's model that have been studied in the literature and their relative behaviour. However, there were no significant improvements in the term structure of credit spreads in these models. In Zhou ${ }^{13}$, the continuous evolution of the asset price process was replaced by a jump diffusion. In this model the asset price can jump and thus default can come as a complete surprise. This model yields credit spreads that are close to spreads seen in the market. However, the solution does not have a closed form expression and has to be obtained using Monte-Carlo simulations which can be time-consuming.

Moreover in the structural approach, the firm's assets are assumed to be tradeable. One of the main limitations with this approach is that the firm's asset values are not observable. This brings us to the important question of implementing these models in practice.

Despite the above criticisms, the structural models have proved to be immensely useful for practitioners in the credit portfolio and credit risk management fields ${ }^{14,15}$. The structural approach attempts to link the valuation of corporate debt to economic fundamentals. Therefore, this
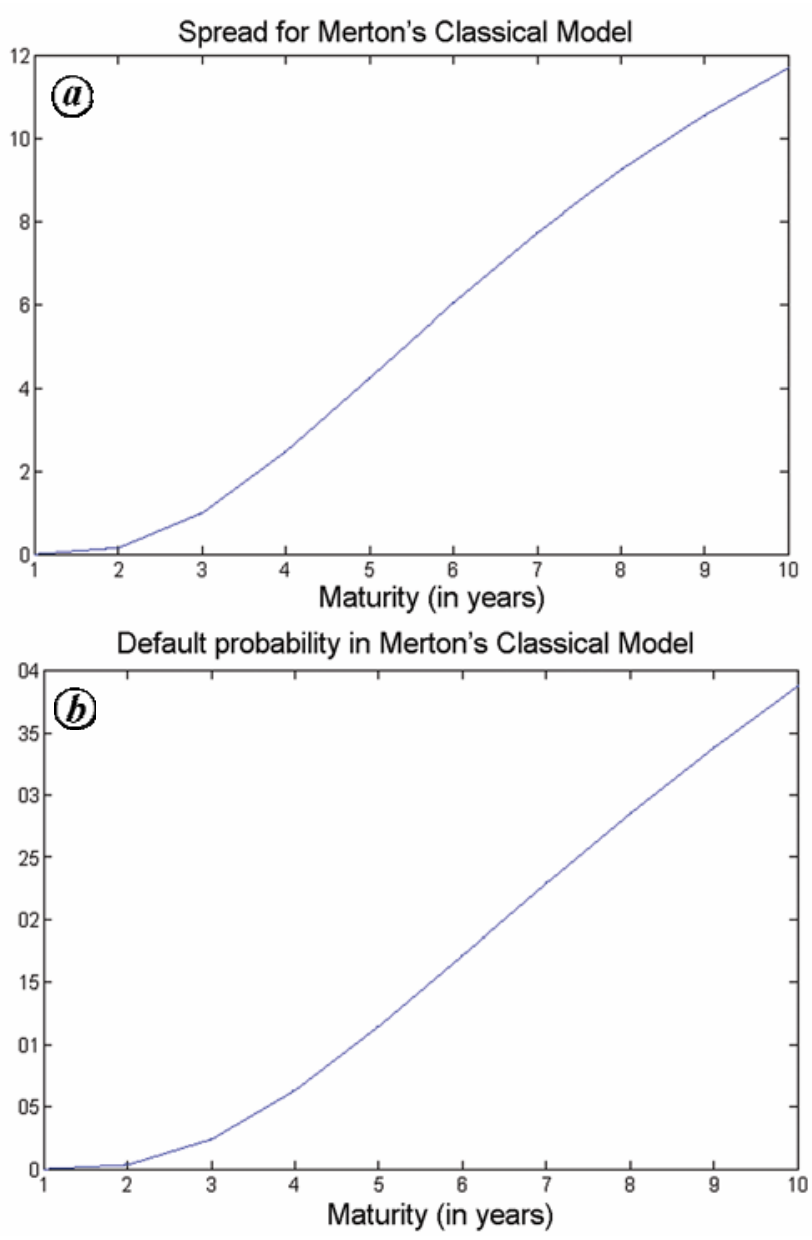

Figure 3. a, Credit spread (Merton) and b, Default probability (Merton).

CURRENT SCIENCE, VOL. 103, NO. 6, 25 SEPTEMBER 2012 
approach is attractive from a financial economics point of view $^{3,14}$. The criticisms about the structural models have been reported in the literature and various solutions proposed $^{3,14-16}$.

Another alternative approach is to model the asset process as a Markov modulated geometric Brownian motion ${ }^{17-21}$. Banerjee et al. ${ }^{17}$ consider the Merton's classical model and some other structural models in a Markov modulated market. They determine the price of defaultable bonds in these models using Föllmer-Schweizer decomposition ${ }^{17}$. The prices are determined as solution to a system of partial differential equations (PDEs) subject to appropriate terminal and boundary conditions. They solve the system of PDEs numerically and observe higher spreads in the Markov modulated market. Furthermore, the switching model captures important financial situations like business cycle, tight liquidity situations and firm restructuring effects, that arise frequently in the financial market. For further details, see ref. 17.

Different methodologies have been developed to resolve the issue of unobservability of the firm's assets in the structural models ${ }^{16}$. As discussed earlier, the Moody's KMV method has turned out to be a popular commercial implementation of the structural credit risk models ${ }^{16}$. The structural models with incomplete accounting information are addressed in the literature ${ }^{22,23}$. Duffie and Lando ${ }^{23}$ assume that a 'noisy' observation of $\left\{A_{t}\right\}$, denoted by $Y_{t}$ is available at finitely many discrete time points $\left\{t_{1}\right.$, $\left.t_{2}, \ldots, t_{n}\right\}$. They assume further that the equity is not traded in the market and derive the conditional distribution of $A_{t}$ given $\left\{Y_{t_{1}}, \ldots, Y_{t_{n}}\right\}$, using Baye's rule. There is another approach using nonlinear filtering theory ${ }^{16,24,25}$ for estimating the parameters in a structural model. For instance, Borkar et al. ${ }^{24}$ point out that though $\left\{E_{t}\right\}$ is theoretically a call option on $\left\{A_{t}\right\}$, the price at which $E_{t}$ is traded in the market may differ from its price according to the option pricing formula due to various 'noise' factors. Therefore, they view $\left\{\log \left(E_{t}\right)+\right.$ 'noise' $\}$ as a process of noisy observations of $\left\{A_{t}\right\}$. They use the theory of nonlinear filtering to recursively estimate the conditional law of $A_{t}$ given the observed equity prices $E_{s}, s \leq t$, for $t \geq 0$. They explicitly derive the likelihood function for the unknown parameters in terms of the nonlinear filter. For details on the filtering approach for estimating parameters in the structural models, see refs 16, 24 and 25.

For credit derivatives based on a large portfolio of assets driven by correlated Brownian motions, the above approach is not mathematically tractable. The only option is to use simulation which can also be quite expensive. In the next section, we describe an alternate approach for modelling credit risk, namely the intensity-based approach.

\section{Intensity-based approach}

We now discuss the pricing of a defaultable bond in the reduced form set-up. Let $\tau$ denote the default time which may be specified using an appropriate stochastic process. Let $r(s)$ and $\lambda(s)$ be stochastic processes denoting the risk-free interest rate and the default intensity respectively. Suppose for simplicity that the recovery is zero, that is, if a default occurs, then the bondholder receives nothing. Then the time 0 price of a defaultable bond maturing at time $T$ given by

$$
D(0, T)=E\left[\exp \left(-\int_{0}^{T} r(s) \mathrm{d} s\right) \mathbf{1}_{\{\tau>T\}}\right] .
$$

The expectation in the above expression and the ones that follow are with respect to the so-called risk-neutral or the pricing probability measure. This measure is usually calibrated, that is, the corresponding model parameters are estimated using market prices of liquid instruments. This is in contrast to estimating parameters from data on past defaults and then deriving a pricing measure from the market measure. After simplifying the above expression ${ }^{11}$ one obtains

$$
D(0, T)=E\left[\exp \left(-\int_{0}^{T}(r(s)+\lambda(s)) \mathrm{d} s\right)\right] .
$$

In order to simplify things further, one needs to specify some models for the interest rate and the default intensity. Some of the simple yet interesting intensity-based models are the mean reverting intensities with jumps ${ }^{26}$, the CIR intensity models ${ }^{26}$, the affine intensity models ${ }^{4,27-33}$ and the HJM forward default rate models ${ }^{34}$. For further details on these models see Duffie and Singleton ${ }^{26}$.

Now we briefly discuss the pricing of CDSs and CDOs. A CDS allows investors to buy protection against the default of a single entity. It is characterized by a unit notional, annualized swap spread $S$, premium payment dates $t_{k}$, and maturity $T$. The cash flow in a CDS consists of two parts; the default leg and the premium leg. The premium leg consists of the payment made by the protection buyer at each date $t_{k}$. The default leg consists of the payment made by the protection seller in the event of a default. The swap spread equates the present value at inception of the premium payments and the present value of the payments at default. After inception, the swap is marked to the market (i.e. its current market value is determined).

An index swap is a generalization of the CDS to a portfolio of defaultable entities. The protection seller pays the protection buyer an amount at each instance of a default in the portfolio. The protection buyer pays an amount at predetermined dates to the protection seller. This premium is a function of the number of entities in the portfolio that have not defaulted at the date the premium is payed. The pricing of an index swap is explained below.

CDOs are a type of structured asset-backed security consisting of a pool of defaultable instruments (loans, 
credits, bonds or default swaps) securitized into one financial instrument. This is suited for investors looking for a narrower risk profile compared to that of an index swap. The pool may consist of hundreds of individual debt instruments. The aggregate loss in a CDO is the sum of all losses due to default. CDO products are exposed to credit risk and interest risk of the underlying instruments. The investors in return for an agreed payment (usually a periodic fee), will bear the losses in the portfolio in the event of a default of the instruments in the portfolio. The CDOs are issued in several tranches, such as the equity, mezzanine and senior tranches.

We illustrate the above concepts using the example of a simple index $\operatorname{swap}^{29}$. To this end, we consider a filtration $\mathcal{F}_{t}$, that represents all the information available at time $t$. For an exact representation of the filtration, see Giesecke $^{29}$. An index swap is a multi-name credit derivative based on a portfolio of $n$ single-name credit swaps. Note that for $n=1$, the pricing formula given below for an index swap reduces to that for a CDS. The constituent swaps have common notional, common maturity $T$ and premium dates $t_{k}$. We normalize the common notional to 1. The swap protection seller has to pay the buyer in case of a default in the reference obligation of a constituent swap. Let $l^{(n)} \in[0,1]$, be the normalized random loss at the $n$th default. The protection seller pays a specified function of the portfolio loss process $L_{t}:=\sum_{n=0}^{N_{t}} l^{(n)}$ where $N_{t}$ counts the total number of defaults in the portfolio. We assume that the loss variables $l^{(n)}$ are drawn independently of one another from a common distribution with mean $l$. The protection buyer receives the loss payments in case of a default and in return pays a premium to the seller to obtain coverage. The cash flows in an index swap with swap spread $S$ (to be determined) are as follows:

(i) Default leg: The portfolio seller covers portfolio losses as they occur, i.e. the increments of the portfolio loss process $L_{t}$.

(ii) Premium leg: The protection buyer pays $S C_{k} \times$ $\left(n-N_{t_{k}}\right)$ at each date $t_{k}$, where $C_{k}$ is the day count fraction.

The value $D_{t}$ at time $t \leq T$ of the index swap default leg is given by the discounted cumulative losses

$$
D_{t}=E\left[\int_{t}^{T} F(t, s) \mathrm{d} L_{s} \mid \mathcal{F}_{t}\right],
$$

where $F(t, s)=\exp (-r(s-t))$ is the discount factor. The quantity $r$ in the discount factor denotes the constant riskfree interest rate. The value at time $t \leq T$ of the premium leg is given by

$$
P_{t}(S)=S \sum_{t_{k} \geq t} C_{k} F\left(t, t_{k}\right)\left[n-E\left(N_{t_{k}} \mid \mathcal{F}_{t}\right)\right]
$$

The fair index swap spread at time $t$ is the solution $S_{t}(T)$ to the equation $D_{t}=P_{t}(S)$. In order to be able to use the above formula, appropriate assumptions need to be made on the evolution of the default-counting process $N_{t}$. For example, under the assumption that the process $N_{t}$ is a doubly stochastic Poisson process (under the risk neutral measure), the default and the premium legs of an index swap can be obtained in terms of certain transforms of the process $N_{t}$ and the loss process $L_{t}$. These transforms can be evaluated under further assumptions that the model parameters satisfy an affine structure. In such a case, the index swap is determined as solutions to a system of ordinary differential equations (ODEs) subject to appropriate terminal conditions. For further details see refs 27, 29-32.

The copula method ${ }^{1}$ is also commonly used for pricing CDOs. However, though copula models are fast and simple, they do not give correct results ${ }^{35}$. For details of pricing CDS and CDO, see refs $11,36,37$. There are also higher-order $\mathrm{CDOs}$ like $\mathrm{CDO}^{2}$ and $\mathrm{CDO}^{3}$. For instance, $\mathrm{CDO}^{2}$ is a contract similar to $\mathrm{CDO}$ where the underlying are the other CDOs instead of simpler risky bonds. However, these higher-order CDOs are extremely difficult to price and were dropped in 2005.

Banerjee et $a .^{27}$ used a Markov chain for modelling the regime-switching economy in the intensity-based approach. The Markov chain can also be used for modelling the credit rating of the firm whose bond we seek to price. Markov chain modelling of credit transition matrices remains the starting point for credit risk modelling ${ }^{38}$. There is considerable literature on estimation of the parameters of the credit migration matrix from market data $^{39,40}$. For further discussions on the reduced form models see refs 11, 26, 36-38.

\section{Conclusion}

In this article, we study some of the basic models for analysing credit risk. In particular, we describe some of the important structural and reduced form models. This field is expanding at a fast pace and requires more sophisticated mathematics. Unfortunately, many people held mathematics responsible for the financial crisis of 2008. They claimed that the models and the math went wrong. There was severe criticism against this point of view from several mathematicians and practitioners all around the globe. For instance, Gregg Berman an expert from Risk Metrics commented (Risk management, The New York Times, 2 January 2009):

'Obviously, we are big proponents of risk models. But a computer does not do risk modelling. People do it. And people got overzealous and they stopped being careful. They took on too much leverage. And whether they had models that missed that, or they weren't paying enough attention, I don't know. But I do think that this was much more a failure of management than of risk management. I think blaming models for this would 
be very unfortunate because you are placing blame on a mathematical equation. You cant blame math.'

The main reason behind the crisis were the mortgagebacked securities as explained in the introduction; see also Sircar ${ }^{35}$. It is unanimously agreed that in order to manage risk and operate the financial market more efficiently, one needs to come up with more sophisticated models. These models may involve much mathematical expertise and therefore the financial world can never separate itself from mathematics.

1. Cherubini, U., Luciano, E. and Vecchiato, W., Copula Methods in Finance, Wiley Finance Series, England, 2004.

2. Hull, J. C., Options Futures and Other Derivatives, Prentice Hall, New Jersey, 2011.

3. Bielecki, T. R. and Rutkowski, M., Credit Risk: Modeling Valuation and Hedging, Springer-Verlag, Berlin, 2002.

4. Giesecke, K., Credit risk modeling and valuation: an introduction. In Credit Risk: Models and Management (ed. Shimko, D.), Risk Books, London, 2004, vol. 2.

5. Black, F. and Cox, J. C., Valuing corporate securities: some effects of bond indentures provisions. J. Finance, 1976, 31, 351367.

6. Kim, I. J., Ramaswamy, K. and Sundaresan, S., The valuation of corporate fixed income securities. In Working Paper, Wharton School, University of Pennsylvania, USA, 2009.

7. Longstaff, F. A. and Schwartz, E., A simple approach to valuing risky fixed and floating rate debt. J. Finance, 1995, 50, 789-821.

8. Merton, R. C., On the pricing of corporate debt: the risk structure of interest rates. J. Finance, 1974, 29, 449-470.

9. Duffie, D. and Singleton, K., Modeling term structures of defaultable bonds. Rev. Financial Stud., 1999, 12, 687-720.

10. Jarrow, R. A. and Turnbull, S. M., Pricing derivatives on financial securities subject to credit risk. J. Finance, 1995, 50, 53-86.

11. Schonbucher, P. J., Credit Derivatives Pricing Models, Wiley Finance, England, 2003.

12. Shreve, S. E., Stochastic Calculas for Finance II, Springer, USA, 2004.

13. Zhou, C., The term structure of credit spreads with jump risk. J. Banking Finance, 2001, 25, 2015-2040.

14. Arora, N., Bohn, J. R. and Zhu, F., Reduced form vs structural models of credit risk: A case study of three models. In The Credit Market Handbook: Advanced Modeling Issues (ed. Fong, H. G.), Wiley, USA, chapter 7, 2006.

15. Schaefer, S. M. and Strebulaev, I. A., Structural models of credit risk are useful: evidence from hedge ratios on corporate bonds. J. Financ. Econ., 2008, 90, 1-19.

16. Duan, J., Gauthier, G. and Simonato, J., On the equivalence of the KMV and maximum likelihood methods for structural credit risk models. In Working Paper, HEC, 2005.

17. Banerjee, T., Ghosh, M. K. and Iyer, S. K., Pricing defaultable bonds in a Markov modulated market. Stoch. Anal. Appl., 2012, 30, 448-475.

18. Basak, G. K., Ghosh, M. K. and Goswami, A., Risk minimizing option pricing for a class of exotic options in a Markov modulated market. Stoch. Anal. Appl., 2009, 29, 259-281.
19. Elliott, R. J., Siu, T. K., Chan., L. L. and Lau, J. W., Pricing options under a generalized Markov modulated jump diffusion model. J. Stoch. Anal. Appl., 2007, 25, 821-843.

20. Elliott, R. J., Chan, L. L. and Siu, T. K., Option pricing and Essecher transform under regime switching. Ann. Finance, 2005, 1, 423-432.

21. Elliott, R. J., Siu, T. K. and Yang, H., Martingale representation for contingent claims with regime switching. Commun. Stoch. Anal., 2007, 1, 279-292.

22. Crouchy, M., Galai, D. and Mark, R., Credit risk revisited. Credit Risk Suppl., 1998, 40-44.

23. Duffie, D. and Lando, D., The term structure of credit spreads with incomplete accounting information. Econometrica, 2001, 69, 633-664.

24. Borkar, V. S., Ghosh, M. K. and Rangarajan, G., Application of nonlinear filtering to credit risk. Oper. Res. Lett., 2010, 38, 527 532.

25. Duan, J. C. and Fulop, A., Estimating the structural credit risk model when equity prices are contaminated by trading noises. J. Econom., 2009, 150, 288-296.

26. Duffie, D. and Singleton, K., Credit Risk: Pricing, Measurement and Management, Princeton University Press, New Jersey, 2003.

27. Banerjee, T., Ghosh, M. K. and Iyer, S. K., Pricing Credit Derivatives in a Markov Modulated Reduced Form Model. Under Review, 2011.

28. Duffie, D., Pan, J. and Singleton, K., Transform analysis and asset pricing for affine jump diffusions. Econometrica, 2000, 68, 13431376.

29. Giesecke, K., An overview of credit derivatives. Jahresber. Deutsch. Math.-Ver., 2009, p. 111.

30. Errais, E., Giesecke, K. and Goldberg, L. R., Affine point process and portfolio credit risk. SIAM J. Finan. Math., 2010, 1, 642-665.

31. Giesecke, K., Goldberg, L. R. and Ding, X., A top-down approach to multi-name credit. Oper. Res., 2011, 59, 283-300.

32. Giesecke, K. and Zhu, S., Transform analysis for point processes and applications in credit risk. Math. Finance, 2011 (forthcoming).

33. Kou, S. and Peng, X., Default clustering and valuation of collateralized debt obligations. In Working Paper, Columbia University, 2009.

34. Heath, D., Jarrow, R. and Morton, A., Bond pricing and the term structure of interest rates: a new methodology for contingent claims valuation. Econometrica, 1992, 60, 77-106.

35. Sircar, R., School on mathematical finance: Introduction. In Public Lecture at TIFR Mumbai, January 2012.

36. Lando, D., Credit Risk Modeling: Theory and Applications, Princeton University Press, New Jersey, 2004.

37. Kane, D. O., Modelling Single-Name and Multi-Name Credit Derivatives, Wiley Finance, England, 2008.

38. Bluhm, C., Overbeck, L. and Wagner, C., An Introduction to Credit Risk Modeling, CRC Financial Mathematics Series, Chapman and Hall, 2002.

39. Jafry, Y. and Schuerman, T., Measuring, estimating and comparing credit migration matrices. J. Banking Finance, 2004, 28 , 2603-2639.

40. Lando, D. and Skodeberg, T., Analyzing rating transitions and rating drift with continuous observations. J. Banking Finance, 2002, 26, 423-444.

ACKNOWLEDGEMENT. This work is supported in part by UGC Centre for Advanced Study. 